\title{
Analysis of a novel spore antigen in Bacillus anthracis that contributes to spore opsonization
}

Correspondence

S. L. Welkos

susan.welkos@amedd.army.mil

Received 22 March 2007

Revised 2 November 2007

Accepted 14 November 2007

\author{
C. K. Cote,† J. Bozue,† K. L. Moody, T. L. DiMezzo, C. E. Chapman \\ and S. L. Welkos
}

Bacteriology Division, United States Army Medical Research Institute of Infectious Diseases (USAMRIID), 1425 Porter Street, Fort Detrick, Frederick, MD 21702, USA
The significance of Bacillus anthracis as an agent of bioterrorism has been well established. An understanding of both the pathogenesis and the host response is required to elucidate approaches to more rapidly detect and effectively prevent or treat anthrax. Current vaccine strategies are focused primarily on production of antibodies against the protective antigen components of the anthrax toxins, which are secreted by the bacilli. A better understanding of the dynamic morphology of the dormant and germinating spore and its interaction with the host immune system could be important in developing an optimally efficacious anthrax vaccine. A spore-associated protein was identified that was specific to the Bacillus cereus group of bacteria and referred to as spore opsonization-associated antigen A (SoaA). Immuno-electron microscopy localized this protein to the area of the cortex beneath the coat of the dormant spore.

Although our data suggested that SoaA was found below the coat layers of the ungerminated spore, SoaA was involved in the interaction of spores with macrophages shortly after infection. To investigate further the specific properties of the SoaA protein, the soaA gene was inactivated in the $B$. anthracis Ames strain. The SoaA protein in the Ames strain of $B$. anthracis increased the phagocytic uptake of the spores in the presence of anti-spore antibodies. Unlike the wild-type strain, the mutant soa $A$ : : Kan strain was not readily opsonized by anti-spore antibodies. While the mutant spores retained characteristic resistance properties in vitro and virulence in vivo, the soa $A$ : : Kan mutant strain was significantly less suited for survival in vivo when competed against the wild-type Ames strain.

\section{INTRODUCTION}

Bacillus anthracis, a spore-forming, Gram-positive bacterium, is the aetiological agent of anthrax (Friedlander, 2000). B. anthracis sporulates in the presence of environmental stresses, such as inadequate nutrient supply or desiccation (Jedrzejas, 2002). The spore, the infectious form of the organism, can remain dormant but viable for decades until favourable conditions are encountered. After infecting an animal host, the spore germinates (Moir et al., 2002), and grows into bacilli that secrete the toxins which ultimately kill the host (Bhatnagar \& Batra, 2001; Brossier \& Mock, 2001).

The currently licensed human vaccine, anthrax vaccine adsorbed (AVA; Biothrax, Bioport), consists of aluminium hydroxide-adsorbed supernatant material, primarily

†These authors contributed equally to this paper.

Abbreviation: PA, protective antigen.

A description of the methods for and results of in silico analysis of the SoaA protein, and a supplementary table listing the oligonucleotide primers used in this study, are available with the online version of this paper. protective antigen (PA), from cultures of a non-encapsulated, toxigenic strain of $B$. anthracis. Biothrax is known to be relatively safe (Joellenbeck \& Hernandez, 2002) and to protect against both cutaneous and inhalational anthrax (Friedlander et al., 1999; Joellenbeck \& Hernandez, 2002; Leppla et al., 2002). Its drawbacks include reactogenicity, the presence of residual lethal factor and oedema factor, which might combine with PA to form active toxins and uncharacterized components, lot-to-lot variation in the amount of $\mathrm{PA}$, and the need for multiple vaccinations to induce and maintain immunity (Brachman et al., 1962). These drawbacks warrant continued efforts to identify novel vaccine strategies. The development of a defined recombinant PA (rPA) vaccine (Farchaus et al., 1998), efforts to reduce the number of doses of AVA required (Pittman et al., 2002), and development of better potency assays (Little et al., 2004) have alleviated some of the problems associated with the current human vaccine; however, there are compelling reasons to warrant development of a new-generation vaccine.

Despite the availability of PA-based vaccines and effective antibiotic therapy against B. anthracis (Friedlander et al., 
2002), the potential exists for the emergence of naturally existing or genetically engineered strains which are antibioticresistant and/or refractory to PA vaccine-induced immunity. To counteract the threat of such potential bioweapons, effective alternative vaccines and therapies should be developed. Better protection might be achieved, for instance, by targeting the early stages of infection by the spore as well as the toxins produced by the vegetative bacilli (Brossier et al., 2002; Cohen et al., 2000; Cote et al., 2005; Welkos et al., 2002). Thus, we hypothesized that a combination of PA and a defined set of spore-associated proteins could contribute to the development of a less reactogenic and more efficacious anthrax vaccine to provide broader coverage against emerging and/or engineered threats.

By characterizing novel spore antigens or defined antigens of unknown immunological significance, we hope to better understand not only spore biology but also the host response to such antigens. In this report, we characterized a protein that is unique to the Bacillus cereus group. We found that this protein was associated with spore opsonization and refer to it as spore opsonizationassociated antigen $\mathrm{A}$ (SoaA).

\section{METHODS}

Reagents, bacterial strains and animals. The fully virulent Ames strain of $B$. anthracis and mutant derivatives were used in this study (Table 1). Escherichia coli strains DH5 $\alpha$ and GM2163 were used for cloning and mutant construction (Table 1). Libraries of B. anthracis Ames strain mini Tn10 insertion mutants were constructed by transposition mutagenesis, as described previously (Day et al., 2007; Gominet et al., 2001; Steinmetz \& Richter, 1994). When appropriate, antibiotics were used at the following concentrations: kanamycin
( $50 \mu \mathrm{g} \mathrm{ml}^{-1}$ for E. coli and $20 \mu \mathrm{g} \mathrm{ml}^{-1}$ for B. anthracis), spectinomycin $\left(125 \mu \mathrm{g} \mathrm{ml} l^{-1}\right.$ for E. coli and $250 \mu \mathrm{g} \mathrm{ml}^{-1}$ for B. anthracis), and erythromycin ( 0.4 or $5 \mu \mathrm{g} \mathrm{ml}^{-1}$ as indicated for B. anthracis). Restriction enzymes and T4 DNA ligase were purchased from New England BioLabs and were used in accordance with the manufacturer's instructions. Pathogen-free $\mathrm{BALB} / \mathrm{c}$ mice were obtained from the National Cancer Institute, Fort Detrick (Frederick, MD). Pathogen-free Hartley guinea pigs were obtained from Charles River Laboratories.

Preparation of spores and anti-spore antibodies. B. anthracis spores were prepared as described elsewhere (Cote et al., 2004, 2005; Welkos et al., 1989). Where indicated, spores were germinated by exposure to a medium containing L-alanine, adenosine and casamino acids (AAC) medium (Welkos et al., 2004) for $1-2 \mathrm{~h}$ at $37^{\circ} \mathrm{C}$. Antispore antibodies (i.e. antibody preparations 733 and 1250) were obtained from the sera of New Zealand white rabbits (Covance) vaccinated with purified preparations of ungerminated spores of the Ames strain that had been inactivated by gamma irradiation before injection, as described previously (Welkos et al., 2004). In addition, a mAb (BA-MAB5) was used for immuno-electron microscopy, Western blots and phagocytosis assays. This mAb was purchased from the Department of Defense Critical Reagent Program maintained under the Joint Program Executive Office for Chemical and Biological Defense. This antibody was provided to the Critical Reagent Program by the Identification Group, Detection Department, Defence Science and Technology Laboratory (Dstl), Porton Down, Wiltshire, UK. This antibody, BA-MAB5, was developed against unfixed purified exosporia (Redmond et al., 2004) from the $B$. anthracis Ames strain. While the precise epitope of BA-MAB5 has not been mapped, it recognizes a protein of $\sim 250 \mathrm{kDa}$ and is presumed to be BclA. Further characterization of the target of BA-MAB5 in this study demonstrates that this mAb does target BclA (Results, Fig. 2 g, h and Western blots; data not shown).

\section{Screening and characterization of the B. anthracis mutant library}

Screening of the mutant library for germination mutants. The libraries of transposon-mutagenized Ames isolates were screened for

Table 1. Bacterial strains and plasmids used in this study

\begin{tabular}{|c|c|c|}
\hline Strain or plasmid & Relevant genotype & Source \\
\hline \multicolumn{3}{|l|}{ E. coli strains } \\
\hline $\mathrm{DH} 5 \alpha$ & & New England Biolabs \\
\hline GM2163 & dam dcm & New England Biolabs \\
\hline \multicolumn{3}{|l|}{ Plasmids } \\
\hline pCR2.1 & TA cloning vector & Invitrogen \\
\hline pEO-3 & E. coli-Bacillus shuttle vector; Erm $^{\mathrm{R}}$ & Mendelson et al. (2004) \\
\hline pJRS102.0 & Source of $\Omega$-Kan-2 cassette & Perez-Casal et al. (1991) \\
\hline $\mathrm{pEO}-3+$ soaA & soaA gene ligated as a NotI/AscI fragment & This study \\
\hline pEO-3+soaA:: $\Omega-$ Kan-2 & $\Omega$-Kan-2 cloned into PmlI site of soaA & This study \\
\hline pEO-3+cylI & cylI gene ligated as a NotI/AscI fragment & This study \\
\hline pEO-3 + cylI:: $\Omega-$ Kan-2 & $\Omega$-Kan-2 cloned into MfeI site of cylI & This study \\
\hline $\mathrm{pEO}-3+g f p$ & $g f p$ cloned into KpnI/HindIII site of pEO-3 & This study \\
\hline pEO-3 + SoaA-GFP & soaA gene cloned into $\mathrm{pEO}-3+g f p$ as a $K p n \mathrm{I} / \mathrm{Pm} \mathrm{II}$ fragment & This study \\
\hline \multicolumn{3}{|l|}{ B. anthracis strains } \\
\hline Ames & Virulent wild-type & Little \& Knudson (1986) \\
\hline Ames-JAB-12 & bclA : : $\Omega$-Kan-2 & Bozue et al. (2007) \\
\hline Ames-JAB-15 & soaA:: $\Omega-$ Kan-2 & This study \\
\hline Ames-JAB-16 & cyll:: $\Omega-$ Kan-2 & This study \\
\hline Ames-JAB-17 & pEO-3 + SoaA-GFP & This study \\
\hline
\end{tabular}


the mutants of interest by a modification of the germination agar overlay method (Clements \& Moir, 1998; Nicholson \& Setlow, 1990). In the modified procedure, the vegetative library was sporulated by culture in Leighton-Doi broth with spectinomycin, and the spores were harvested and purified as described above. Single colonies of the spore library were inoculated by patching onto a filter placed on a new sporulation medium (NSM) agar plate (Phillips \& Ezzell, 1989) containing spectinomycin. After patching 50 colonies to each plate, the latter were wrapped in foil and incubated at $37{ }^{\circ} \mathrm{C}$. After $24 \mathrm{~h}$ at $37^{\circ} \mathrm{C}$, they were transferred to room temperature for several days to complete sporulation, which was determined by phase-contrast microscopy. The filters were each then transferred to agar plates containing D-alanine (Nicholson \& Setlow, 1990; Clements \& Moir, 1998 ) and the plates were heated in an oven for $2 \mathrm{~h}$ at $65{ }^{\circ} \mathrm{C}$. The filters were then transferred to plates of germination agar (GA), prepared as described elsewhere (Clements \& Moir, 1998) or after supplementation with AAC medium (Welkos et al., 2004). The filters on the GA were overlaid with molten $0.8 \%$ soft agar containing antispore antibodies and the plates were then incubated at $37^{\circ} \mathrm{C}$. The patch plates were screened for mutants that germinated more rapidly than the wild-type parental strain in the presence of the antibodies and thus formed red colonies in contrast to the white or pink colonies formed by isolates that were more sensitive to antibody-mediated germination inhibition or were slower to germinate. In this method, germinating spores were detected by their ability to reduce the colourless tetrazolium dye contained in the GA medium to a red formazan derivative (Nicholson \& Setlow, 1990; Clements \& Moir, 1998).

Characterization of the germination of library mutants. The rate and extent of germination of the library mutants compared to those of the parent strain were assessed further in several assays, including the microtitre spectrofluorometric assay of fluorescent dye uptake during germination (Welkos et al., 2004), determination of heat resistance (Welkos et al., 2004), determination of changes in refractility by phase-contrast microscopy (Welkos et al., 2004), and measurement of changes in $\mathrm{OD}_{590}$ (Clements \& Moir, 1998).

Cloning and identification of mutated sequences. The transposondisrupted gene sequences in selected mutants were identified by standard rescue cloning procedures. Chromosomal DNA was isolated from the mutant $B$. anthracis strain as described elsewhere (Keim et al., 1997; Jackson et al., 1997) and digested with HindIII, and the digested DNA was self-ligated. The ligated DNA was butanolprecipitated and electroporated into E. coli. Plasmids were isolated from selected colonies on spectinomycin-containing agar plates and the plasmids were sequenced using the Thermo Sequenase Dye Terminator Cycle Sequencing pre-mix kit (Amersham BioScience). The sequences obtained were compared to those in the GenBank database. As determined by BLAST searches of the cloned DNA versus the GenBank entry (accession no. 47530577) for the B. anthracis strain Ames genome, the transposon insertion described in this paper occurred in an ORF that encodes a protein of unidentified function (B. anthracis hypothetical protein BA5269).

\section{Construction of mutant $B$. anthracis strains}

B. anthracis soaA::Kan. A $1.5 \mathrm{~kb}$ DNA fragment containing the soaA gene was PCR-amplified using the primer pair SoaA-NotI and SoaA-AscI (see Supplementary Table S1 available with the online version of this paper) from Ames chromosomal DNA, and cloned into the shuttle vector $\mathrm{pEO}-3$, as detailed previously (Bozue et al., 2005; Mendelson et al., 2004), and the soaA gene was interrupted with the $\Omega$-Kan-2 fragment (Perez-Casal et al., 1991) at a unique PmlI site within the gene. The Ames strain of $B$. anthracis was then transformed with the plasmid containing soaA::Kan as described previously (Mendelson et al., 2004). The plasmid was next integrated into the chromosome and the cointegrates were selected on the basis of antibiotic (kanamycin) and temperature $\left(42{ }^{\circ} \mathrm{C}\right)$ resistance (Mendelson et al., 2004). Eight kanamycin-resistant colonies were selected and streaked onto two separate plates each containing an antibiotic: kanamycin (to select for the presence of the $\Omega$-Kan-2 fragment) and erythromycin ( $5 \mu \mathrm{g} \mathrm{ml}^{-1}$; to detect pEO-3). One of the clones was resistant to kanamycin but sensitive to erythromycin. This putative mutant clone, strain Ames soaA:: Kan, was confirmed by PCR analysis using the primer pairs SoaA 5' and OL289 and SoaA3' and OL289 listed in Supplementary Table S1.

Construction of the cyll::Kan B. anthracis mutant. A $3 \mathrm{~kb}$ DNA fragment containing the cylI gene (BA5268), which encodes a putative cytoloysin immunity domain protein with homology to the CylI protein from Enterococcus faecalis (Coburn et al., 1999), was PCRamplified from Ames strain chromosomal DNA and cloned into vector pEO-3 using the primer pair CylI-NotI and CylI-AscI. The cloned cylI gene was inactivated at the MfeI restriction enzyme site by inserting the $\Omega$-Kan- 2 fragment. The plasmid was transformed and integrated into the chromosome of the Ames strain as described above. Putative cylI mutants in the Ames strain were confirmed by PCR analysis using the primer pairs CylI5' and OL289 and CylI 3' and OL289 listed in Supplementary Table S1.

RT-PCR analyses. RNA was isolated and RT-PCR was performed using the One-step RT-PCR kit (Qiagen) as described previously (Cote et al., 2005). The primer pair SoaA-Lower and SoaA-Upper was used to detect mRNA from the soaA gene. The primer pair CytoLower and Cyto-Upper was used to detect mRNA from the cylI gene. The primer pair SoaA-intergenic and Cyto-intergenic was used to verify that the soaA and cylI genes were located on a single transcript. The primer pair SoaA5' and BA5270 was used to show that the BA5270 gene and the soaA gene were located on a single transcript. Primers used in the RT reactions are included in Supplementary Table S1.

Macrophage assays for spore phagocytosis and intracellular viability. RAW264.7 cells were cultured in 24-well trays with coverslips and used in phagocytosis and intracellular spore viability assays as described previously (Cote et al., 2005; Welkos et al., 2001, 2002). The cell cultures were infected with spores at an m.o.i. of 1-2 spores per macrophage. To promote spore binding and phagocytosis by the macrophages, the infected cell cultures were centrifuged at low speed at $260 \mathrm{~g}$ for $30 \mathrm{~min}$ at $30{ }^{\circ} \mathrm{C}$ and incubated for an additional 30 min at $37{ }^{\circ} \mathrm{C}$ in $5 \% \mathrm{CO}_{2}$. As described by Banks et al. (2005), they were then incubated for $30 \mathrm{~min}$ at $37{ }^{\circ} \mathrm{C}$ in medium containing $10 \%$ fetal bovine serum and $5 \mu \mathrm{g}$ gentamicin $\mathrm{ml}^{-1}$ then extensively washed to remove most of the unphagocytosed spores. The effects of antibodies on phagocytosis and intracellular spore germination and viability were assayed bacteriologically by viable-count determinations and by light and immunofluorescence microscopy of stained samples (Cote et al., 2005; Welkos et al., 2001, 2002). Samples were stained with spore stain (malachite green) and counterstained with a Wright-Giemsa stain (Diff-Quik) (Welkos et al., 1989) for light microscopy. For immunofluorescence microscopy, coverslips were incubated with a rabbit antibody prepared against whole killed spores of the Ames strain that recognizes ungerminated and germinated spores as well as bacilli, and the spores were detected by doublelabelling with secondary antibodies, as described previously (Cote et al., 2005; Welkos et al., 2002).

Protein purification and antibody production. Recombinant proteins were produced by the James Madison University Center for Integrated Science and Technology (Harrisonburg, VA). Several strategies were employed to express and purify the SoaA protein. The ORF encoding the full-length SoaA protein (236 aa) was amplified and cloned into the protein expression vector pTYB2 (New England 
Biolabs) using primers GBAAf1 and GBAAr236 (Supplementary Table S1). Because the untagged full-length protein was insoluble (data not shown), several different fragments of the SoaA protein were cloned into pTYB12 (IMPACT-CN system, New England Biolabs) to express a soluble portion of the protein by creating a protein-intein fusion product. The fusion proteins were purified over a chitin column, which bound the intein tag (Goodin et al., 2005). DNA fragments encoding the full-length protein (amino acids 1236), or amino acids 35-236, 141-193 or 141-236, were amplified and cloned into pTYB12. The $6 \mathrm{kDa}$ peptide consisting of amino acids 141-193 was soluble; however, the other three fusion proteins remained insoluble. The DNA encoding the soluble peptide (referred to as $6 \mathrm{kDa}$ SoaA) was amplified by using the primers GBAAf141 and GBAAr193 (Supplementary Table S1). Full-length (untagged) SoaA protein was purified as inclusion bodies using B-PER bacterial protein purification reagent as described by the manufacturer (Pierce Biotechnology) and the $6 \mathrm{kDa}$ SoaA peptide was expressed and purified as an intein fusion protein (Goodin et al., 2005). Based on hydropathy and antigenicity plots, this segment was predicted to be highly antigenic.

Rabbits were vaccinated (by Covance as described above) with either the insoluble inclusion bodies containing the SoaA protein or the soluble $6 \mathrm{kDa}$ SoaA peptide. The Ribi-adjuvant system (Corixa) was used and the vaccination strategy was that recommended by the manufacturer. The antisera obtained were IgG-purified, as described previously (Welkos et al., 2004). In addition, prebleed rabbit sera (collected before vaccination) were also IgG-purified and served as negative controls in our assays, where indicated.

Electron microscopy. Immuno-electron microscopy was used to observe spores as described previously (Cote et al., 2005). The sections were incubated in primary antibody after it had been normalized to $1 \mathrm{mg} \mathrm{ml}^{-1}$ and diluted $1: 100$ (final concentration $10 \mu \mathrm{g} \mathrm{ml}^{-1}$ ). The primary antibodies included rabbit anti-spore polyclonal antibody 733 , rabbit anti-SoaA polyclonal antibody, rabbit anti-6 $\mathrm{kDa} / \mathrm{SoaA}$ antibody and normal pre-immune rabbit IgG as a negative control. Negative controls were normal non-immune rabbit IgG. Additional sections not treated with primary antibody were prepared to test the specificity of secondary antibodies. All sections were treated with blocking buffer and gold-labelled secondary antibodies.

Construction of GFP fusions. A GFP fusion vector $p E O-3-g f p$ was constructed by cloning a KpnI/HindIII fragment containing the $g f p$ mut2 gene (Lemon \& Grossman, 1998) into the KpnI/HindIII site of pEO-3 (Bozue et al., 2005; Mendelson et al., 2004). To construct a translational C-terminal fusion of SoaA to GFP, the soaA gene was amplified using primers soaA-GFP $3^{\prime}$ and soaA-KpnI GFP 5' (Supplementary Table S1) utilizing Phusion DNA polymerase (New England Biolabs). The PCR product was cloned into the KpnI/PmeI sites of vector pEO-3-gfp. The resultant plasmids were passaged through E. coli strain GM2163 and electroporated into the Ames strain of $B$. anthracis. The plasmid was cointegrated into the chromosome to produce a translational fusion.

Protein electrophoresis and Western blotting. Spore extracts were prepared by homogenizing spores in extraction buffer containing urea [0.05 M dithioerythritol, $1 \%$ SDS, $8 \mathrm{M}$ urea in $0.005 \mathrm{M}$ cyclohexyl aminomethane sulfonic acid (CHES), pH 9.8; UDS] (Pandey \& Aronson, 1979). Briefly, spores were suspended in UDS and homogenized in a Bio 101 Fast Prep (Qbiogene) using lysing matrix B tubes. The spore lysate was transferred to a fresh tube and centrifuged, and the supernatant fluid was saved for further analysis. The proteins in the supernatant fluids were separated on a $4-20 \%$ Tris-glycine mini gel (Invitrogen) and stained with Gel Code Blue (Pierce). The proteins were electroblotted onto PVDF membranes in
$20 \%$ methanol, $0.3 \%$ SDS and Tris-glycine transfer buffer (Pierce). Membranes were blocked in a $5 \%$ non-fat milk solution and then incubated with a commercially available affinity-purified rabbit antiGFP polyclonal serum (ICL) at a dilution of $1: 2000$, or polyclonal IgG directed against gamma-irradiated spores at a dilution of $1: 500$. After washing, the membranes were incubated with an anti-rabbit horseradish peroxidase-conjugated secondary antibody diluted $1: 4000$ or $1: 10000$ (Pierce). Immunoreactive bands were visualized using 4-chloronaphthol/3,3'-diaminodbenzidine (4CN/DAB) substrate (Pierce).

Comparisons of in vitro resistance and growth. Spores were subjected to several adverse conditions to ascertain the resistance properties of the soaA:: Kan mutant spores compared to those of the Ames parent spores. Spores were exposed to $100 \%$ methanol, proteinase $\mathrm{K}\left(30 \mu \mathrm{g} \mathrm{ml}^{-1}\right)$, lysozyme $\left(250 \mu \mathrm{g} \mathrm{ml}^{-1}\right), \mathrm{HCl}(1,0.5$ and $0.25 \mathrm{M}), \mathrm{NaOH}(1,0.5$ and $0.25 \mathrm{M})$ or chloroform $(10 \%)$ for $30 \mathrm{~min}$. The spores were then washed and plated to assess viability. In addition, the effect of extended periods at elevated temperatures was also examined. For this assay, spores were incubated at $70{ }^{\circ} \mathrm{C}$ and aliquots were removed to determine the amount of time required to achieve a $90 \%$ loss of viability (Bozue et al., 2005).

To compare the in vitro growth rates of the wild-type Ames and soaA:: Kan strains, $25 \mathrm{ml} \mathrm{LB}$ cultures were each inoculated with $\sim 5 \times 10^{6}$ spores of both strains. The cultures were incubated at $37{ }^{\circ} \mathrm{C}$ with aeration and aliquots were removed at selected time points $(0,2$, 6 and $10 \mathrm{~h}$ ). The aliquots were mixed by vortexing, diluted then plated onto LB plates with or without kanamycin.

\section{Effects of the soaA ::Kan mutation on virulence and in vivo} fitness. To assess potential alterations in virulence associated with the soaA::Kan mutation, we utilized both a mouse intraperitoneal model and a guinea pig intramuscular model of infection. Mice were challenged intraperitoneally with varying doses of spores (Cote et al., 2004). Guinea pigs were challenged intramuscularly (Bozue et al., 2005; Fellows et al., 2001) with approximately five $\mathrm{LD}_{50}$ doses (Ames equivalents) of either wild-type Ames strain spores or soaA::Kan spores. The guinea pig in vivo fitness model was utilized as described previously (Bozue et al., 2007). Briefly, Hartley guinea pigs were challenged intramuscularly with approximately equal challenge doses of wild-type Ames spores and mutant spores (either soaA::Kan or cyll:: Kan). Two days later, spleens were harvested from moribund guinea pigs and the bacterial load was quantified for each spleen. The relative percentage recovery was calculated by determining the percentage of mutant bacteria (based upon antibiotic resistance) recovered from the spleen relative to the percentage of mutant spores present in the initial challenge dose. The same procedure was also performed with infections initiated with a single $B$. anthracis strain (either wild-type Ames or soaA:: Kan).

Passive protection studies. Approximately 12-week-old female $\mathrm{BALB} / \mathrm{c}$ mice received intraperitoneal injections of purified rabbit IgG that was directed against whole irradiated spores (1250) or against recombinant SoaA (anti-SoaA), or normal pre-immune IgG. Another group received PBS as a control. The $\operatorname{IgG}(300 \mu \mathrm{g})$ was injected approximately $5 \mathrm{~h}$ prior to an intraperitoneal spore challenge with approximately five lethal doses of $B$. anthracis Ames strain spores (Popov et al., 2004). Mice were observed for 14 days.

Statistical and sequence analysis program tools. Survival rates were compared between each treatment group and the control group by Fisher exact tests with permutation adjustment for multiple comparisons. Kaplan-Meier/product-limit estimation was used to construct survival curves and to compute mean survival times. Survival curves were compared between each treatment group and the control group by log rank tests with Hochberg adjustment for 
multiple comparisons. Mean times-to-death were compared between each treatment group and the control group by $t$ tests with permutation adjustment for multiple comparisons. The above analyses were conducted using SAS version 8.2 (SAS OnlineDoc version 8; SAS Institute). The in vitro germination kinetics of spores in different peritoneal fluids was analysed by a four-parameter logistic regression model available in the SigmaPlot PC software program (Welkos et al., 2004). When comparing relative bacterial counts recovered from spleens, statistical significance $(P<0.05)$ was determined by the two-tailed Student's $t$ test with the GraphPad Prism software (GraphPad). DNA sequence analysis was performed using DNASTAR and the NCBI BLASTP program was used to identify homologues in other bacteria.

\section{RESULTS}

\section{Characterization of the soaA gene}

The gene encoding SoaA was isolated in a screen of a Tn 10 mutagenesis library of $B$. anthracis Ames strain spores for mutants that exhibited resistance to the germination inhibitory activity (GIA) of antibodies to intact ungerminated spores (Cote et al., 2005; Welkos et al., 2004). The soaA gene (BA5269), encoding a 'hypothetical protein', was $724 \mathrm{bp}$ in length and was $43 \mathrm{bp}$ upstream of a gene (BA5268) that shares homology to the cytolysin immunity gene (cylI) from Ent. faecalis. In Ent. faecalis, the CylI protein protects the bacterium from being damaged by the cytolysins that it produces (Coburn et al., 1999) (Fig. 1a). The CylI homologue in B. anthracis exhibited approximately $29 \%$ identity and $47 \%$ similarity with the Ent. faecalis CylI protein, as well as significant identity with homologues in B. cereus and Bacillus thuringiensis ( 99 and $94 \%$, respectively). In addition, a small ORF (BA5270) was located immediately upstream of the soaA gene. This gene was shown to have significant homology with putative DNA-binding proteins from B. cereus ( $97.5 \%$ identity) (Rasko et al., 2004) and B. thuringiensis (98.7\% identity) (Challacombe et al., 2007). These three genes shown in Fig. 1(a) (BA5270, 5269 and 5268) are maintained in the same order in B. cereus (BCE-5169, 5168 and 5167) and B. thuringiensis (BT 9727-4739, 4738 and 4737). BA5270 is in a different reading frame to soaA, but the coding sequences of these genes overlap by $\sim 15 \mathrm{nt}$ (Johnson \& Chisholm, 2004). A putative sigma-K $\left(\sigma^{\mathrm{K}}\right)$-dependent promoter sequence (Amaya et al., 2001) was located upstream of BA5270 (Fig. 1b). RT-PCR demonstrated that the BA5270, soaA and cylI genes could be cotranscribed (data not shown).

The SoaA protein contained an internal $6 \mathrm{kDa}$ region that was suggested by hydrophobicity analysis to be hydrophilic and potentially antigenic (data not shown). Antibodies were raised against the SoaA protein and this $6 \mathrm{kDa}$ SoaA peptide. The online version of this paper contains data obtained through in silico analyses that supplement the characterization of the SoaA protein. Briefly, these analyses suggested that the relatively hydrophobic SoaA protein appears to contain five transmembrane regions that are potentially associated with a bacterial membrane, possibly the inner spore membrane.

\section{Localization of the SoaA protein}

Electrophoretic analyses comparing whole-spore extracts from wild-type Ames spores and soaA:: Kan spores did not reveal any changes in spore coat protein profiles (data not shown). Using polyclonal antibodies directed against recombinant SoaA (and the $6 \mathrm{kDa}$ hydrophilic portion of

(a)
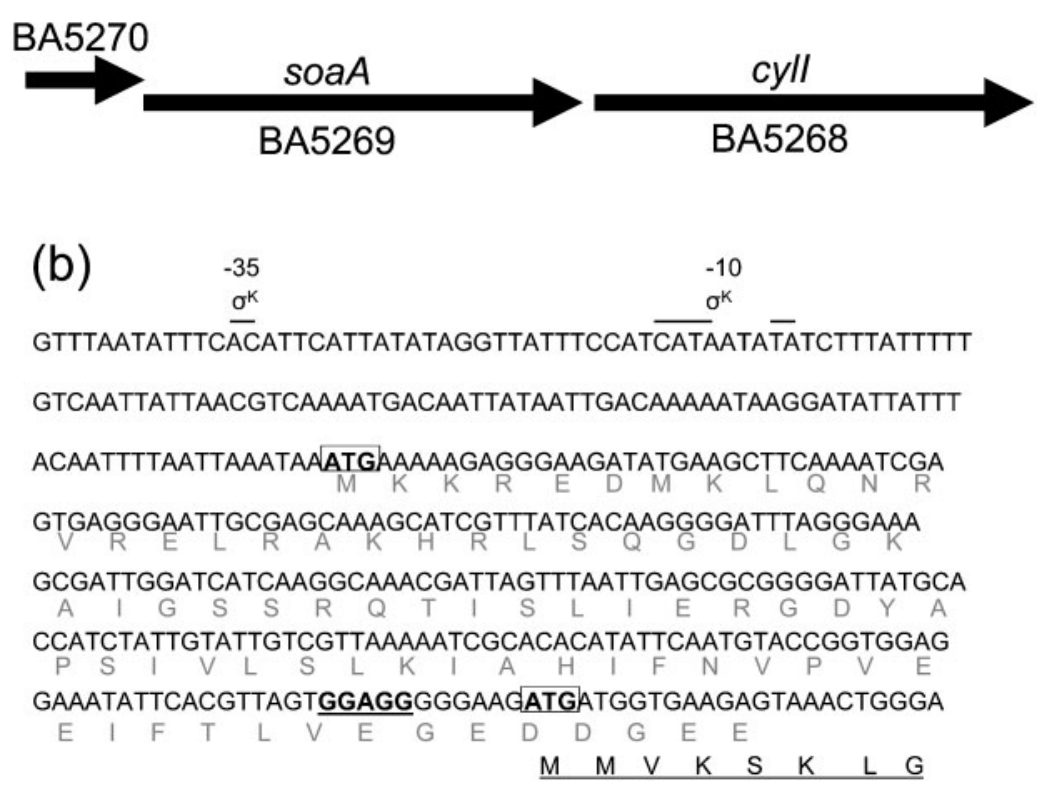

Fig. 1. Characterization of the soa $A$ gene. (a) The gene arrangement of BA5270, soa $A$ and cyll. This arrangement is conserved in $B$. thuringiensis and $B$. cereus. (b) Sequence data from the soa $A$ gene (BA5269) and a small ORF upstream (BA5270). Overlined bases represent the putative consensus $\sigma^{\mathrm{K}}$ promoter sequence, putative initiation codons are in bold type and boxed, a putative RBS is in bold underlined type (no obvious RBSs were noted upstream of BA5270), underlined amino acids in black type represent the first amino acids encoded by the soa $A$ gene, and amino acids in grey type represent those encoded by BA5270. 


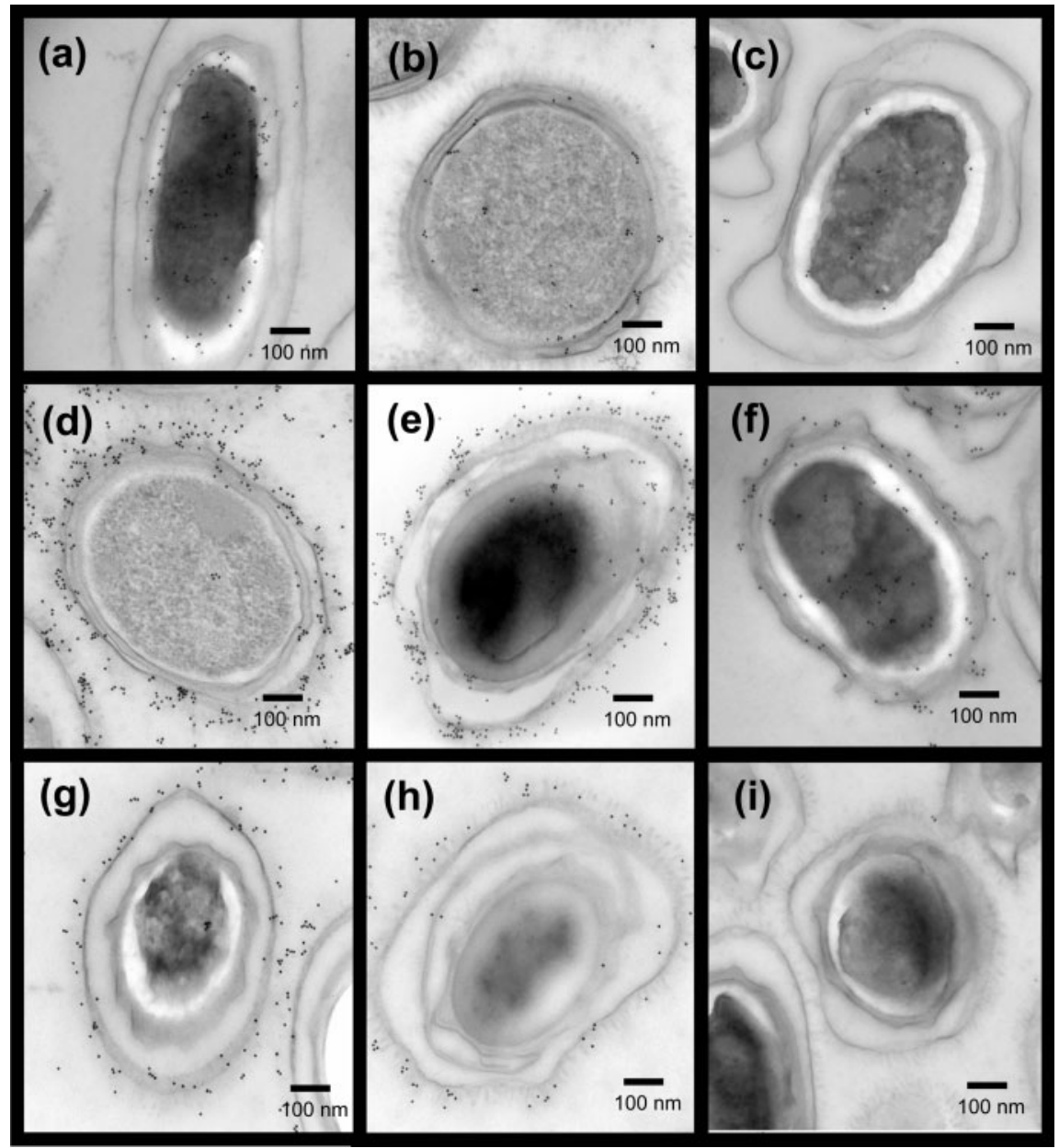

Fig. 2. Localization of proteins by immuno-electron microscopy. Polyclonal antibodies directed against SoaA bound entities localized to the area of the cortex beneath the spore coat of ungerminated wild-type Ames spores (a). However, germinated Ames spores apparently contained lower levels of SoaA, as suggested by the decrease in staining by polyclonal antisera directed against SoaA of the germinated spores (b). The soaA : : Kan mutant spores exhibited residual binding of the anti-SoaA antibodies (c); however, this binding was significantly less than that of the wild-type spores. Antibodies against gammairradiated spores (anti-spore antibody 733) predominantly stained exosporium (mainly BclA-containing fibres) in both germinated (d) and ungerminated (data not shown) wild-type Ames spores. Similar levels of staining were observed when soaA : Kan spores were examined (e). In addition, the polyclonal IgG 733 also labelled non-BclA spore epitopes, as shown when $b c / A$ : : Kan spores were visualized (f). An anti-BclA mAb (BA-MAB5) was also used, and similar levels of staining were observed when wild-type $(\mathrm{g})$ or soaA::Kan $(\mathrm{h})$ spores were visualized. Pre-immune $\lg \mathrm{G}$ was used to stain wild-type Ames spores for control purposes (i).

SoaA), the protein was localized to the area of the cortex underneath the spore coat of the ungerminated wild-type spore by immuno-electron microscopy (Fig. 2a). Ungerminated spores contained more of the SoaA protein than germinated spores, as suggested by the decrease in staining of the latter $(112 \pm 25$ gold particles per spore, $n=18$ spores, Fig. $2 \mathrm{a}$, and $33 \pm 12$ gold particles per spore, $n=17$ spores, Fig. $2 \mathrm{~b}$, respectively). These differences in the presence of SoaA on the spores were statistically significant $(P<0.001)$. These data suggest that the SoaA protein is either degraded or released to the surface during germination. The soaA::Kan mutant spores retained negligible levels of binding to anti-SoaA antibodies ( $15 \pm 7$ gold particles per spore, $n=18$, Fig. 2c). This low level of binding could be due to the production of a predicted small 72 aa peptide in our mutant strain. It is possible that this peptide was produced and detected by the polyclonal anti-SoaA antibodies. This small peptide, however, did not contain the proposed immunodominant $6 \mathrm{kDa}$ peptide of the SoaA protein.

Further immuno-electron microscopy analyses illustrated that the anti-SoaA staining pattern is different from that observed using an anti-spore IgG. This anti-spore IgG is directed predominantly against the BclA protein (the immunodominant protein of $B$. anthracis spores described 
by Steichen et al., 2003; Sylvestre et al., 2002), which is located on the surface of the spore and forms the 'hair-like' projections from the exosporium (Fig. 2d). The soaA:: Kan mutant spores also stained similarly with the anti-spore antibodies (Fig. 2e). Lastly, we examined spores of the BclA knockout mutant of the Ames strain (bclA::Kan) (Bozue et al., 2007) with anti-whole spore IgG (Fig. 2f). These data obtained from micrographs confirmed that the BclA protein is immunodominant in the immune response generated against gamma-irradiated spores, but also reaffirmed that other non-BclA antigens are recognized (Fig. 2f).

One possible effect of the absence of a functional SoaA protein could be alterations in the expression of BclA on the surface of the spores. To further characterize potential alterations in the expression of BclA in the soaA::Kan mutant spores, wild-type Ames spores and soaA::Kan spores were stained with a mAb against BclA (Fig. 2g, h, respectively). It was determined that there was no significant difference in binding of the $\mathrm{mAb}$ to wild-type spores or soaA:: Kan spores $(79 \pm 24$ gold particles, $n=22$, and $74 \pm 22$ gold particles, $n=16$ for wild-type and soaA:: Kan spores, respectively). It is also noteworthy that all of the staining patterns observed in these electron micrographs, described above, were significantly different from that for pre-bleed IgG $(2.3 \pm 2.8$ gold particles per spore, $n=30$ spores, Fig. $2 \mathrm{i}$ ).

Western blot analyses were also carried out to identify any putative differences in BclA expression that could be attributed to the soaA::Kan genotype. When either polyclonal or monoclonal antibodies were used, the Western blots indicated no appreciable differences in BclA expression on the soaA:: Kan spores compared to the wild-type spores, regardless of whether the spores were refractile or germinated (data not shown).

To further characterize the location of the SoaA protein, we created a $B$. anthracis strain containing a translational SoaA :: GFP fusion. Experiments involving the SoaA :: GFP fusion illustrated that soaA expression was mainly associated with sporulating cultures. Non-sporulating exponential-phase vegetative cultures did not express GFP (Fig. 3a, two left panels). However, cultures that had begun to sporulate (overnight stationary-phase cultures) did exhibit GFP expression (Fig. 3a, two right panels, and Fig. 3b). GFP was most obviously expressed in bacilli without a clearly visible mature spore, suggesting that the SoaA protein is incorporated into the forespore by the mother cell relatively early in spore assembly (Fig. 3b). This was also predicted by the presence of a putative $\sigma^{\mathrm{K}}$ dependent promoter sequence (Fig. 1a) which is associated with gene expression during sporulation (Helmann \& Moran, 2002).

Western blot analyses were also performed using extracts of germinated spores and an anti-GFP antibody. Spores from the Ames wild-type and Ames SoaA::GFP fusion strains were germinated and mechanically disrupted. Western

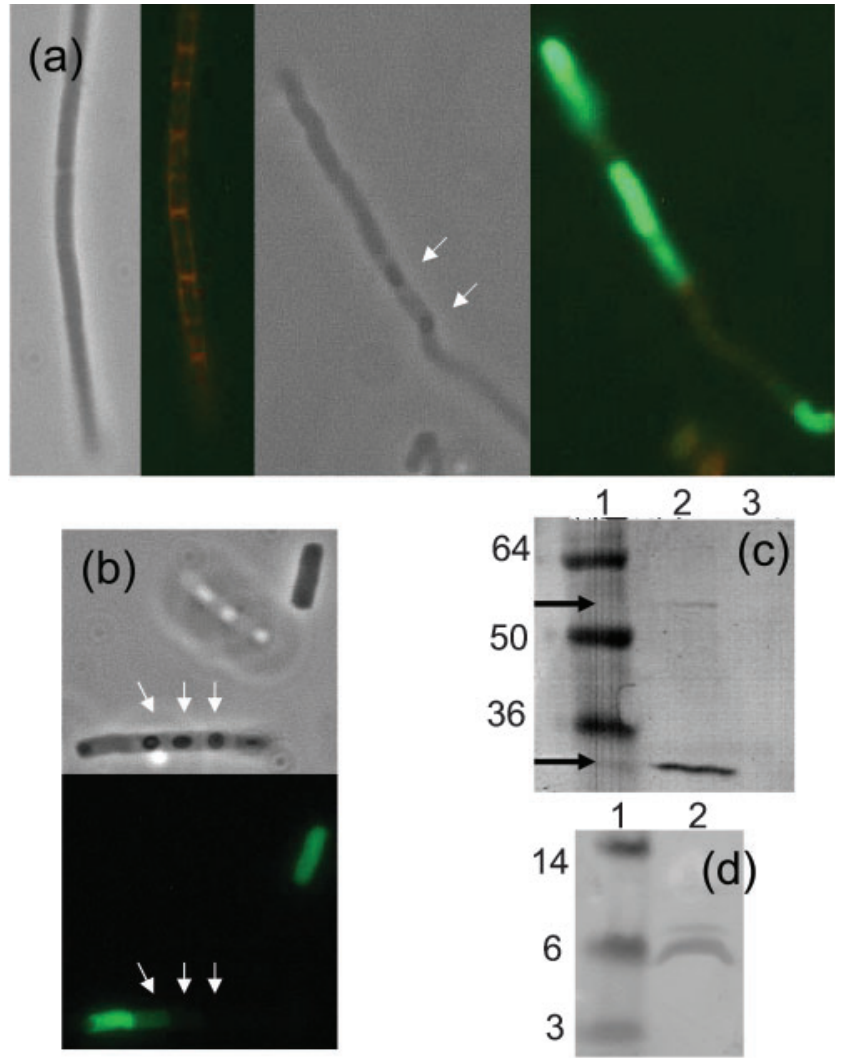

Fig. 3. SoaA expression is associated with sporulating cultures. The SoaA : : GFP fusion was not expressed in the early stage/nonsporulating bacilli observed in a $4 \mathrm{~h}$ culture [a red membranespecific counter stain FM4-64 (Molecular Probes) was also used] in LB medium (a, left two panels), but was expressed at high levels during sporulation (spores marked by white arrowheads), as demonstrated in an overnight culture in LB medium (a, right two panels). The SoaA : :GFP fusion seemed to be expressed at the highest intensities in bacilli that did not contain a mature spore (spores marked by white arrowheads) (b). Western blots identified the SoaA : : GFP fusion in extracts of germinated spores containing the SoaA : : GFP fusion construct (c, lane 2) but not in those of the Ames wild-type strain (c, lane 3 ). The black arrows indicate the SoaA: :GFP fusion protein $(\sim 55 \mathrm{kDa})$ and GFP $(\sim 28 \mathrm{kDa})$ as detected using an anti-GFP antibody. Western blot analyses also determined that the $6 \mathrm{kDa}$ hydrophilic/antigenic peptide of SoaA is recognized by $\lg G$ directed against ungerminated gammairradiated spores (d, lane 2).

blots revealed a band representing the SoaA:: GFP fusion $(\sim 55 \mathrm{kDa})$ in the Ames spores containing the SoaA : GFP fusion, but not in the wild-type spores (Fig. 3c). Western blot analyses also detected a band representing GFP alone. This GFP band is likely to be the result of sporulationassociated proteases that cleave the GFP domain from the SoaA:: GFP fusion construct. Similar instances of the cleavage of the GFP domain from GFP fusion constructs have been reported previously (Kim et al., 2006; Little \& Driks, 2001). SoaA::GFP concentrations in extracts 
prepared from ungerminated spores were below the level of detection by Western analysis (data not shown). However, IgG directed against gamma-irradiated ungerminated spores did react with the $6 \mathrm{kDa}$ recombinant peptide that was shown to be hydrophilic and likely antigenic (Fig. 3d). It has been shown that gamma irradiation induces significant membrane permeabilization in Bacillus spores (Laflamme et al., 2004). Thus, we hypothesize that the SoaA protein present beneath the coat in ungerminated spores becomes available to the immune system upon gamma irradiation. Conceivably, this IgG directed against gamma-irradiated spores may better represent the entire pool of spore epitopes that could be seen by the infected host from spore inhalation to spore germination and eventual outgrowth.

\section{Effects of the soaA : : Kan mutation on spore resistance properties}

Spores were exposed to $\mathrm{HCl}, \mathrm{NaOH}$, lysozyme, proteinase $\mathrm{K}$, methanol, chloroform and extended periods at an elevated temperature. There were no significant differences observed in the resistance properties of the soaA::Kan spores as compared to Ames parental spores under any conditions tested (data not shown). These results suggest that the SoaA protein does not contribute significantly to the resistance of spores exposed to these deleterious experimental conditions.

\section{Effects of the soaA : : Kan mutation on spore germination}

As determined by phase-contrast microscopy (Welkos et al., 2004), spectrofluorometric germination assays (Welkos et al., 2004) and the decrease in OD (Paidhungat \& Setlow, 1999), there were no significant differences in in vitro germination rates of the Ames wild-type and soaA:: Kan spores (data not shown). However, the wild-type and mutant spores differed in their germination potential when loss of heat resistance was used as a germination marker. Briefly, spores were exposed to germinants for selected amounts of time, and then exposed to $65{ }^{\circ} \mathrm{C}$ for $30 \mathrm{~min}$. The heated samples were then diluted and the dilutions plated to assess spore viability after heating (Welkos et al., 2004). The ability of the soaA::Kan mutant to germinate more readily than the wild-type as reflected by the loss of heat resistance (loss of viability) was observed to be statistically significant in five individual experiments. In one representative experiment, after a $5 \mathrm{~min}$ exposure to the germination medium, the wild-type Ames spores were determined to be $73.6 \% \pm 2.3 \%$ germinated (heat-sensitive), while the soaA::Kan spores were determined to be $89.2 \% \pm 1.4 \%$ germinated (heat-sensitive) $(P=<0.0001)$. In contrast, as detected in these germination assays, the cylI:: Kan mutant germinated to the same extent as the wild-type Ames strain (data not shown). These results suggested that a secondary reduction in expression of CylI was probably not the cause of phenotypic changes associated with disruption of the soaA mutant.

\section{Effects of the soaA : : Kan mutation on spore opsonization}

Antibodies directed against gamma-irradiated ungerminated spores (antibody 733) can have opsonic effects on wild-type Ames spores, resulting in an enhancement of phagocytosis compared to that of wild-type spores treated with prebleed IgG (Fig. 4a; S. L. Welkos and others, unpublished data). In contrast, as observed with the transposon mutant originally isolated, the antibody exhibited little ability to enhance phagocytosis of the soaA::Kan mutant spores (Fig. 4a). These conclusions were supported by viable count determinations of infected macrophages (Fig. 4) and also microscopically, by spore and histological staining and by double-label fluorescent immunostaining (data not shown).

Similar results were obtained when the effects of antibodies directed against the SoaA protein were assessed. These antibodies stimulated the uptake of wild-type Ames strain spores by the RAW264.7 macrophage cell line; however, the mutant soaA::Kan spores were resistant to opsonization stimulated by the presence of the anti-SoaA IgG (Fig. 4b). In addition, using the $\mathrm{IgG}$ fraction from antisera directed against a small hydrophilic portion of the SoaA protein (anti-6 kDa-SoaA), we observed the same enhanced opsonization associated with these antibodies as we observed with antibodies to whole spores and to the full-length SoaA protein (Fig. 4c). We also examined the opsonization of $b c l A:$ :Kan spores by the anti-spore antibody (733). Spores of the $b c l A:: K a n$ mutant were also not significantly opsonized by the anti-spore antibodies (Fig. 4d).

We also determined the effect of anti-SoaA antibodies on the phagocytosis of $b c l A::$ Kan spores. As predicted by earlier experiments, the $b c l A::$ Kan spores are not opsonized by anti-SoaA antibodies, although wild-type spores are (Fig. 4e). These results were expected, as IgG directed against whole irradiated spores did not opsonize the bclA:: Kan spores (Fig. 4d). To further explore the possible relationship between SoaA and BclA, we examined the effects of an anti-BclA mAb (MAB-5) on the phagocytosis of soaA:: Kan spores (Fig. 4f). This $\mathrm{mAb}$ was opsonic for both wild-type and soaA::Kan spores. Microscopy and protein analysis suggested that soaA::Kan spores retain native levels of BclA (Fig. 2 g, h; data not shown).

In addition, we examined the effects of anti-PA antibodies on the opsonization of the soaA::Kan spores. Pretreating soaA:: Kan spores with anti-PA IgG significantly increased the phagocytic uptake of the soaA::Kan spores (data not shown). This anti-PA antibody-associated enhanced uptake of the mutant spores was similar to that observed with wild-type Ames spores, as shown previously (Cote et al., 2005; Welkos et al., 2002). This result suggests that the differences between the soaA::Kan spores and wild-type spores in their responses to the opsonizing activity of antispore antibodies are likely to be specific to $\operatorname{IgG}$ directed against the exosporium and/or other spore components and not to IgG directed against PA. 

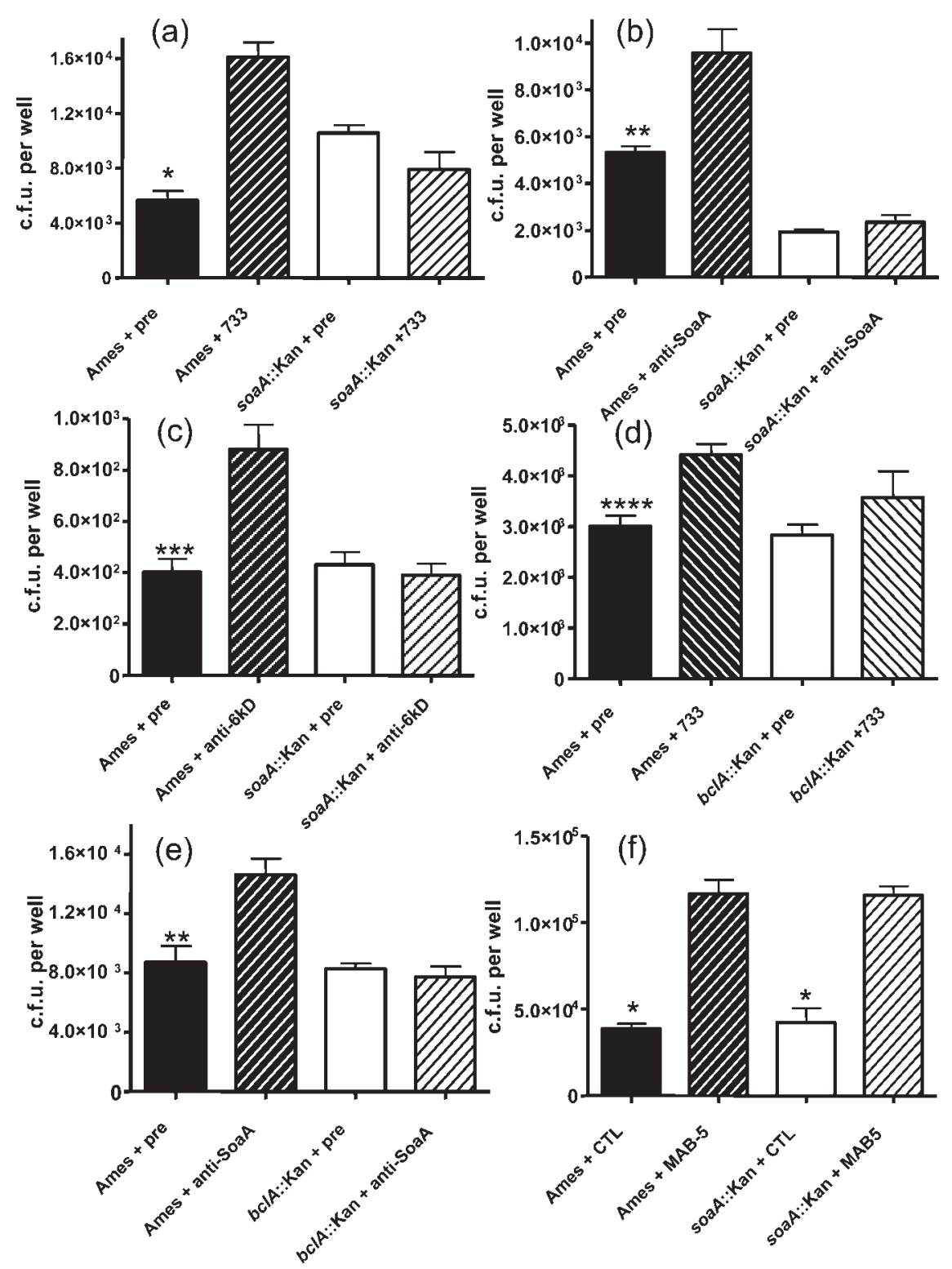

Fig. 4. Effect of the soaA : : Kan mutation on the opsonization of spores by macrophages with lgG. As shown by viable counts, the wild-type Ames spores were significantly opsonized by lgG directed against gamma-irradiated ungerminated spores (rabbit polyclonal antibody 733) (a, d). However, the soa $A$ : : Kan spores were resistant to this opsonization (a). As shown in the in vitro spore-phagocytosis assays, wild-type Ames spores were readily opsonized by antibodies directed against either the full-length SoaA protein (b) or the hydrophilic $6 \mathrm{kDa}$ portion of the SoaA protein (c). However, spores of the soaA:: Kan strain were not significantly affected by the presence of the anti-SoaA $\operatorname{lgG}(\mathrm{b})$ or the anti-6 kDa $\operatorname{lgG}$ (c). Spores of the bc/A : : Kan strain were not significantly opsonized by polyclonal $\lg G 733$ (d). The effect of anti-SoaA antibodies on bclA::Kan spores was also examined. bclA : : Kan spores were not significantly opsonized by anti-SoaA antibodies, unlike wild-type spores (e). An anti-BclA mAb (BA-MAB5) was equally opsonic for wild-type and soaA::Kan spores ( $f$ ). An anti-Junin virus mAb (CTL) was used for control purposes (f). Representative data are shown and similar results were obtained in at least three experiments. ${ }^{\star} P<0.0001$, ${ }^{\star *} P=0.001,{ }^{* \star *} P=0.0002,{ }^{* \star \star *} P=0.0003$.

\section{Effects of the soaA : Kan mutation on virulence and in vivo fitness of the bacterium}

To assess potential alterations in virulence associated with the soaA::Kan mutation, we utilized both a mouse intraperitoneal (Cote et al., 2004; Popov et al., 2004) and a guinea pig intramuscular model of infection (Bozue et al., 2005; Fellows et al., 2001). All guinea pigs challenged with approximately five Ames $\mathrm{LD}_{50}$ equivalents of either wildtype Ames or soaA:: Kan spores succumbed to the ensuing 
infection within 4 days (data not shown). In our mouse intraperitoneal model of infection, varying doses were administered (ranging from approximately 0.5 Ames $\mathrm{LD}_{50}$ equivalents to six Ames $\mathrm{LD}_{50}$ equivalents). There was no statistically significant difference noted in virulence between the wild-type spores and the soaA::Kan spores (data not shown).

To further explore the potential phenotypes associated with spores of the mutant soaA:: Kan strain, we employed an in vivo competition assay. Guinea pigs were infected with approximately equal challenge doses of Ames parent spores and mutant spores (soaA::Kan or cylI::Kan). Two days post-challenge, moribund guinea pigs were euthanized and the spleens were harvested. Bacterial loads in the spleens were determined, and the ratio of parent to mutant bacilli recovered (based on antibiotic resistance) was determined.

The cylI::Kan strain was able to survive in vivo at comparable levels to those observed for the Ames parental strain (Fig. 5). Interestingly, however, the soaA : : Kan strain appeared to be significantly less suited for survival in vivo $(P<0.0001)$ compared to the wild-type Ames strain (Fig. 5). When control competitive experiments were performed in vitro with the Ames strain and the soaA::Kan mutant strain, no differences in bacterial growth and survival were observed (data not shown).

It remains unclear what stage of pathogenesis was affected by the soaA::Kan mutation. To further address this phenotype, however, we performed single-infection

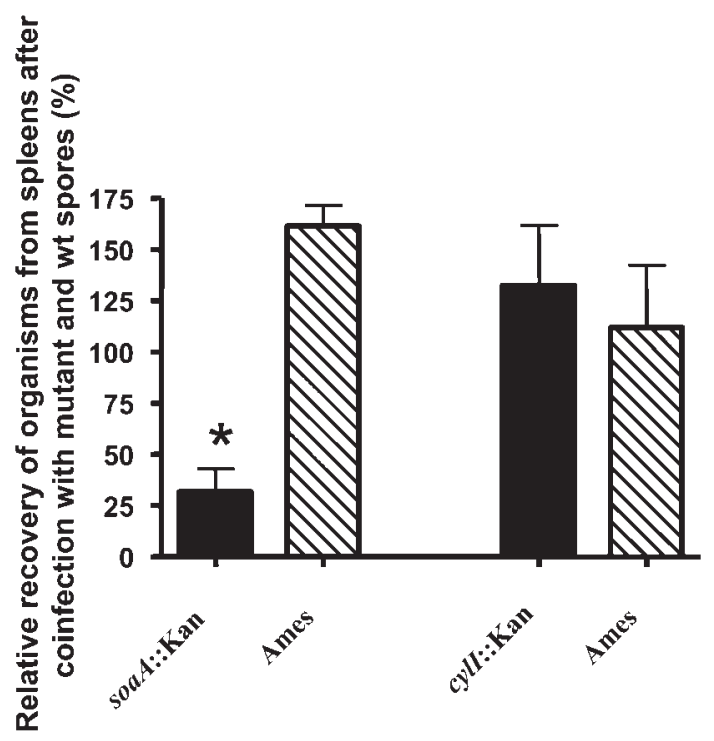

Fig. 5. The effect of the soa $A$ : : Kan mutation on in vivo fitness in a competitive guinea pig infection model. In vivo fitness assays demonstrated that the soaA::Kan strain, while still virulent, was significantly less suited than the wild-type Ames strain to survival in vivo in a guinea pig intramuscular challenge model $(n=10$; ${ }^{\star} P<0.0001$ ). The cyll: : Kan mutation did not significantly alter in vivo fitness of the bacteria $(n=12)$. experiments in which the guinea pigs were infected with either Ames wild-type spores or soaA:: Kan spores. Spleens were harvested from moribund animals and the splenic bacterial load was determined for each animal. Previous data from our laboratory and that of others (A. Scorpio and A. Friedlander, personal communication) have suggested that the splenic bacterial load in moribund guinea pigs infected with the wild-type Ames strain is very consistent at approximately $3 \times 10^{9}$ c.f.u. $\mathrm{g}^{-1}$ of spleen. In this experiment, the splenic load of wild-type Ames strain-infected animals was determined to be $3.3 \times 10^{9}$ c.f.u. (g spleen $)^{-1}\left[ \pm 9.4 \times 10^{8}\right.$ c.f.u. $\left.(\text { g spleen })^{-1}, n=3\right]$ and the splenic load associated with infection with soaA:: Kan spores was determined to be $2.9 \times 10^{9}$ c.f.u. (g spleen $)^{-1}\left[ \pm 7.3 \times 10^{8}\right.$ c.f.u. (g spleen) $\left.{ }^{-1}, n=7\right]$. This slight difference was statistically insignificant $(P=0.4)$. These data illustrate, however, that when single infections are examined there are no significant defects noted in the pathogenesis of soaA:: Kan spores. When coinfections are initiated, the soaA:: Kan spores are significantly less suited to compete with wild-type Ames spores in the guinea pig model.

\section{Passive protection using rabbit IgG directed against spore epitopes}

Passive protection studies were carried out to determine if rabbit IgG directed against irradiated spores or SoaA would offer protection from an intraperitoneal infection with $B$. anthracis spores. As shown in Fig. 6, there was significant protection afforded to the mice by anti-irradiated spore IgG when compared to a PBS buffer control (percentage survival $P=0.0296$ and survival curve $P=0.0153$ ). However, when compared to IgG purified from preimmune normal rabbit sera, these differences were modest and statistically insignificant $(P>0.05)$. Anti-SoaA IgG did not significantly protect the mice when compared to either the PBS or the pre-immune IgG controls $(P>0.05)$.

\section{DISCUSSION}

A novel, spore-associated antigen from $B$. anthracis was identified. This protein had no previously assigned putative function and thus is listed as a 'hypothetical protein' in the annotated complete genome of the Ames strain of $B$. anthracis (Read et al., 2003). The mutation in this gene was isolated during our attempts to identify proteins that were recognized in vitro by antisera directed against spore entities with potential roles in the early events of in vivo spore germination and the host response.

The soaA mutant was isolated from a library of transposonmutagenized Ames spores and was identified in a screen for mutants resistant to the germination inhibition activity of anti-spore antibodies. To analyse its characteristics in detail, an allelic exchange mutation was made in the soa $A$ gene. The soaA::Kan mutant strain of $B$. anthracis Ames strain exhibited several interesting phenotypes. The SoaA 


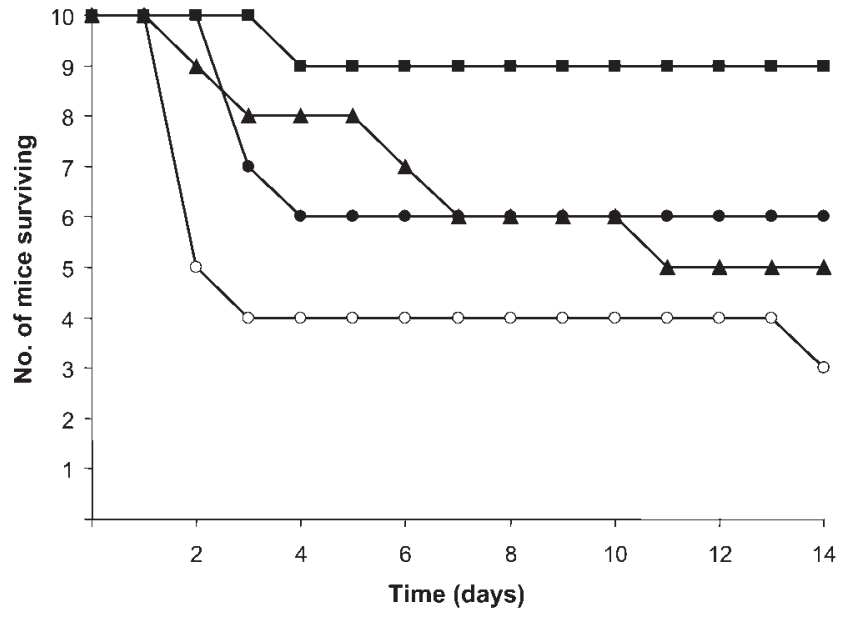

Fig. 6. Passive protection of mice with purified rabbit anti-spore $\lg$. Mice received intraperitoneal injections of PBS $(\bigcirc), 300 \mu \mathrm{g}$ anti-spore $\lg G(\boldsymbol{\square}), 300 \mu \mathrm{g}$ anti-SoaA $\lg G(\boldsymbol{\Delta})$ or $300 \mu \mathrm{g}$ preimmune rabbit $\lg G(\bullet)$. Five hours later, the mice received $\sim 2200$ spores intraperitoneally. Mice were observed for 14 days to collect mortality data. These data are representative and similar results were obtained in three independent experiments.

protein appeared to be deposited onto the spore early in sporulation (Fig. 3), and in ungerminated spores the SoaA protein was located in the area of the cortex underneath the spore coat, possibly the inner spore membrane (Fig. 2a). Our data suggest that the SoaA protein was released, degraded during germination (Fig. 2b), or exposed by some other mechanism on or near the surface of the germinating spore in a manner that affected sporemacrophage interactions. This release or degradation of SoaA appeared to coincide with the hydrolysis of the spore cortex during germination.

It has been noted that the inner membrane of the spore expands significantly during germination. The inner spore membrane of Bacillus species can expand as much as twofold during the first minutes of germination (Cowan et al., 2004). The SpoVAD protein described by Vepachedu \& Setlow (2005) is an integral membrane protein with seven transmembrane domains that is localized to the inner spore membrane of Bacillus subtilis. Although the SpoVAD protein shares no homology with the SoaA protein, the authors noted that there was an approximately two- to threefold decrease in the amount of SpoVAD found in germinated/outgrown spores as compared to dormant spores (Vepachedu \& Setlow, 2005). This observation is similar to our data regarding SoaA levels in germinated spores compared to ungerminated spores of $B$. anthracis.

However, Western blot analyses detected the SoaA ::GFP fusion in germinated spores (Fig. 3d) but not in ungerminated spores (data not shown). We believe that our extraction procedures are adequate to lyse the ungerminated spores, as we can efficiently detect nucleic acids from these lysed spore samples (Cote et al., 2005). One hypothesis concerning this apparent failure of SoaA detection via Western blot analyses of ungerminated spores is that the SoaA protein is cross-linked to other spore components and in a form that cannot be readily resolved by SDS-PAGE until germination is initiated.

We hypothesized that this protein plays some role in antigen expression on the surface of the spore upon initiation of germination, thus affecting spore and antispore IgG interactions. Importantly, however, the soluble $6 \mathrm{kDa}$ SoaA peptide was recognized by IgG directed against gamma-irradiated ungerminated Ames spores (Fig. 3d), confirming that the SoaA protein is associated with ungerminated spores and was possibly made accessible to the immune system upon gamma irradiation (Laflamme et al., 2004).

We observed that spores of the soaA:: Kan strain were not readily opsonized in the presence of rabbit polyclonal antispore IgG, whereas the phagocytosis of wild-type spores was significantly stimulated in the presence of such antibodies (Fig. 5a). The antibodies directed against ungerminated spores were composed predominantly of antibodies to the immunodominant exosporium antigen BclA (Fig. 2c, d), although other spore antigens were also recognized (Fig. 2f) (Steichen et al., 2003, 2005; Sylvestre et al., 2002, 2005). We observed that bclA::Kan spores were also not significantly opsonized by anti-spore IgG when compared to wild-type Ames strain spores (Fig. 4d). Even though BclA remained present on the exosporium of the soaA::Kan spores, these mutant spores were not significantly opsonized by $\operatorname{IgG}$ directed against wild-type ungerminated Ames spores. It is possible that the SoaA protein affected $\mathrm{BclA}$ in a way that alters opsonic properties associated with BclA.

To further explore this potential relationship between BclA and SoaA, we performed additional phagocytosis assays. We examined the impact of anti-SoaA antibodies on the phagocytic rates of $b c l A:$ : Kan spores (Fig. 4e) as well as the effect of an anti-BclA $\mathrm{mAb}$ on the phagocytosis of soaA:: Kan spores (Fig. 4f). Not surprisingly, anti-SoaA antibodies did not opsonize bclA::Kan spores. These results were predicted, since IgG against whole irradiated spores (already shown to contain antibodies against SoaA, Fig. 3d) also did not opsonize the bclA::Kan spores. Interestingly, the anti-BclA $\mathrm{mAb}$ did opsonize the soaA:: Kan spores at similar levels to those observed with the wild-type spores (Fig. 4f). There are several possible reasons why the mAb opsonizes the soaA::Kan spores and polyclonal rabbit IgG against irradiated spores does not. In addition to being raised/elicited in two different animal species, the $\mathrm{mAb}$ was raised against unfixed purified exosporium and the polyclonal IgG was generated in response to whole irradiated spores. The BclA presentation to the host immune response is likely to be quite different when utilizing these two different methods of antigen preparation. Nonetheless, our results suggest that several 
spore antigens, including SoaA and BclA, contribute to opsonization with polyclonal antisera.

We also observed that antibodies directed against the SoaA protein could affect wild-type spores (Fig. 4b, c). The observation that the anti-SoaA IgG stimulated phagocytosis of wild-type spores (but not of the soaA:: Kan mutant) (Fig. 4b), like that of anti-whole irradiated spore antibodies (Fig. 4a), supports the hypothesis that the SoaA protein can be found on the surface, at least transiently, and is immunogenic. The observation that antibodies against the small soluble $6 \mathrm{kDa}$ portion of the protein significantly facilitated spore phagocytosis by macrophages argues that this hydrophilic region is a surface-exposed and/or immunodominant segment of the SoaA protein that is recognized by the immune response to gamma-irradiated spores (Fig. 3d).

The apparent release or degradation of SoaA appeared to occur during the process of germination, as discussed above. Conceivably, this might have influenced the early events in germination or spore trafficking in vivo, such as those that were involved in the decreased fitness observed in infected guinea pigs (Fig. 5). Specifically, while inactivating the soaA gene did not alter virulence in a statistically significant manner in mice or guinea pigs (data not shown), the soaA::Kan mutant appeared to be significantly less suited for survival when competed against the wild-type Ames strain within the guinea pig host (Fig. 5). As shown in vitro, the spores of the soaA:: Kan strain retained most resistance phenotypes that were measured in this study, and the vegetative cells grew at similar rates to those of the Ames strain (data not shown). However, the soaA::Kan spores were observed to have an altered germination phenotype as determined by loss of heat resistance. While this germination phenotype was undetectable by other germination assays, the loss of heat resistance may constitute an alteration of a relatively early stage of spore germination. These data suggest that the mutant spores germinate more readily or more rapidly than wild-type spores. At the very least, the soaA::Kan spores lose the characteristic heat-sensitivity more rapidly than wild-type spores. However, we hypothesize that this germination phenotype reflects an alteration towards the end of the initial stage I of germination but before the commencement of stage II of germination which involves metabolic activation (Moir et al., 2002). These coinfection data illustrate that the subtle, yet consistently significant, 'hyper-germination' phenotype in the soaA::Kan spores may result in a significant disadvantage when coinfections are initiated with soaA::Kan spores and wild-type spores. Perhaps the germinating soaA::Kan spores are more rapidly disposed of by the innate immune system than the wild-type Ames spores. This could theoretically allow a greater percentage of Ames spores to survive the host immune response, eventually leading to the greater amounts of Ames bacilli present in moribund animals. It is important to note that while some fraction of the soaA::Kan spore population could be more rapidly disposed of, the surviving spores remain capable of initiating a fatal infection when single $B$. anthracis strains are used to initiate infections.

This and other studies highlight the potential of an immune response generated against spore-specific epitopes. It has been demonstrated directly and indirectly by several groups that, in addition to toxin antigens, spore entities also have a protective role in the immune response to an anthrax infection (Brossier et al., 2002; Cohen et al., 2000; Enkhtuya et al., 2006; Glomski et al., 2007; Hahn et al., 2005; Kudva et al., 2005; Welkos et al., 2001).

While rabbit polyclonal IgG directed against SoaA did not significantly protect mice from challenge with Ames spores when compared to pre-immune IgG (Fig. 6), these studies did offer new insight into heterologous passive protection experiments. Although mice passively immunized with rabbit IgG were modestly protected against a $B$. anthracis infection, the protection was not specific to antibodies directed against B. anthracis (Fig. 6). Protection was only observed when the mice immunized with rabbit anti-spore IgG were compared to mice given buffer alone and was not significant in comparison to mice immunized with preimmune rabbit IgG. These findings potentially clarify an ongoing debate about the efficacy of anti-spore antibodies in passive protection studies (Goossens et al., 2007; Enkhtuya et al., 2007). Using their homologous passive protection model, Glomski et al. (2007) showed that antispore antibodies are not sufficient to protect mice from an infection. However, Enkhtuya et al. (2006), using their heterologous passive protection model, showed that rabbit antibodies can significantly protect mice from an infection when compared to a buffer control. Our data demonstrated that the passive protection seen with rabbit antispore $\operatorname{IgG}$ in mice was at least partly non-specific.

A better understanding of spore morphology and sporehost interactions may be critical for establishing improved vaccines and therapies for $B$. anthracis. To counteract engineered and emerging threats, we must identify and exploit multiple bacterial targets involved in several stages of pathogenesis, including spore infection, bacillary replication and intoxication.

\section{ACKNOWLEDGEMENTS}

The research described herein was sponsored by the Medical Biological Defense Research Program, US Army Medical Research and Materiel Command, project 02-4-5C-023 (S. L. W.) and 02-4-5C018 (J. B.). We thank G. Rother for his invaluable technical assistance and S. Norris for her expert statistical analysis. We would also like to thank Dr Adam Driks and his laboratory for helpful discussions on spore morphology and GFP fusion construction, as well as Dr Anne Moir for her expert advice concerning spore germination. Opinions, interpretations, conclusions, and recommendations are those of the authors and are not necessarily endorsed by the US Army. Research was conducted in compliance with the Animal Welfare Act and other federal statutes and regulations relating to animals and experiments involving animals, and adheres to the principles stated in the Guide for the Care and Use of Laboratory Animals, National Research 
Council, 1996. The facility where this research was conducted is fully accredited by the Association for Assessment and Accreditation of Laboratory Animal Care.

\section{REFERENCES}

Amaya, E., Khvorova, A. \& Piggot, P. J. (2001). Analysis of promoter recognition directed by $\sigma^{\mathrm{F}}$ of Bacillus subtilis by using randomsequence oligonucleotides. J Bacteriol 183, 3623-3630.

Banks, D. J., Barnajian, M., Maldonado-Arocho, F. J., Sanchez, A. M. \& Bradley, K. A. (2005). Anthrax toxin receptor 2 mediates Bacillus anthracis killing of macrophages following spore challenge. Cell Microbiol 7, 1173-1185.

Bhatnagar, R. \& Batra, S. (2001). Anthrax toxin. Crit Rev Microbiol 27, 167-200.

Bozue, J. A., Parthasarathy, N., Phillips, L. R., Cote, C. K., Fellows, P. F., Mendelson, I., Shafferman, A. \& Friedlander, A. M. (2005). Construction of a rhamnose mutation in Bacillus anthracis affects adherence to macrophages but not virulence in guinea pigs. Microb Pathog 38, 1-12.

Bozue, J., Cote, C. K., Moody, K. L. \& Welkos, S. L. (2007). Fully virulent Bacillus anthracis does not require the immunodominant protein, BclA, for pathogenesis. Infect Immun 75, 508-511.

Brachman, P. S., Gold, H., Plotkin, S. A., Fekety, F. R., Werrin, M. \& Ingraham, N. R. (1962). Field evaluation of a human anthrax vaccine. Am J Public Health 52, 632-645.

Brossier, F. \& Mock, M. (2001). Toxins of Bacillus anthracis. Toxicon 39, 1747-1755.

Brossier, F., Levy, M. \& Mock, M. (2002). Anthrax spores make an essential contribution to vaccine efficacy. Infect Immun 70, 661-664.

Challacombe, J. F., Altherr, M. R., Xie, G., Bhotika, S. S., Brown, N., Bruce, D., Campbell, C. S., Campbell, M. L., Chen, J. \& other authors (2007). The complete genome sequence of Bacillus thuringiensis $\mathrm{Al}$ Hakam. J Bacteriol 189, 3680-3681.

Clements, M. O. \& Moir, A. (1998). Role of the gerI operon of Bacillus cereus 569 in the response of spores to germinants. J Bacteriol 180, 6729-6735.

Coburn, P. S., Hancock, L. E., Booth, M. C. \& Gilmore, M. S. (1999). A novel means of self-protection, unrelated to toxin activation, confers immunity to the bactericidal effects of the Enterococcus faecalis cytolysin. Infect Immun 67, 3339-3347.

Cohen, S., Mendelson, I., Altboum, Z., Kobiler, D., Elhanany, E., Bino, T., Leitner, M., Inbar, I., Rosenberg, H. \& other authors (2000). Attenuated nontoxinogenic and nonencapsulated recombinant Bacillus anthracis spore vaccines protect against anthrax. Infect Immun 68, 4549-4558.

Cote, C. K., Rea, K. M., Norris, S. L., van Rooijen, N. \& Welkos, S. L. (2004). The use of a model of in vivo macrophage depletion to study the role of macrophages during infection with Bacillus anthracis spores. Microb Pathog 37, 169-175.

Cote, C. K., Rossi, C. A., Kang, A. S., Morrow, P. R., Lee, J. S. \& Welkos, S. L. (2005). The detection of protective antigen (PA) associated with spores of Bacillus anthracis and the effects of anti-PA antibodies on spore germination and macrophage interactions. Microb Pathog 38, 209-225.

Cowan, A. E., Olivastro, E. M., Koppel, D. E., Loshon, C. A., Setlow, B. \& Setlow, P. (2004). Lipids in the inner membrane of dormant Bacillus species are largely immobile. Proc Natl Acad Sci U S A 101, 7733-7738.

Day, W. A., Jr, Rasmussen, S. L., Carpenter, B. M., Peterson, S. N. \& Friedlander, A. M. (2007). Microarray analysis of transposon insertion mutations in Bacillus anthracis: global identification of genes required for sporulation and germination. J Bacteriol 189, 3296-3301.

Enkhtuya, J., Kawamoto, K., Kobayashi, Y., Uchida, I., Rana, N. \& Makino, S. (2006). Significant passive protective effect against anthrax by antibody to Bacillus anthracis inactivated spores that lack two virulence plasmids. Microbiology 152, 3103-3110.

Enkhtuya, J., Makino, S., Uchida, I. \& Kawamoto, K. (2007). In reply Microbiology Comment. Microbiology 153, 302-304.

Farchaus, J. W., Ribot, W. J., Jendrek, S. \& Little, S. F. (1998). Fermentation, purification, and characterization of protective antigen from a recombinant, avirulent strain of Bacillus anthracis. Appl Environ Microbiol 64, 982-991.

Fellows, P. F., Linscott, M. K., Ivins, B. E., Pitt, M. L., Rossi, C. A., Gibbs, P. H. \& Friedlander, A. M. (2001). Efficacy of a human anthrax vaccine in guinea pigs, rabbits, and rhesus macaques against challenge by Bacillus anthracis isolates of diverse geographical origin. Vaccine 19, 3241-3247.

Friedlander, A. M. (2000). Anthrax: clinical features, pathogenesis, and potential biological warfare threat. Curr Clin Top Infect Dis 20, 335-349.

Friedlander, A. M., Pittman, P. R. \& Parker, G. W. (1999). Anthrax vaccine: evidence for safety and efficacy against inhalational anthrax. JAMA 282, 2104-2106.

Friedlander, A. M., Welkos, S. L. \& Ivins, B. E. (2002). Anthrax vaccines. Curr Top Microbiol Immunol 271, 33-60.

Gardy, J. L., Spencer, C., Wang, K., Ester, M., Tusnády, G. E., Simon, I., Hua, S., deFays, K., Lambert, C. \& other authors (2003). PSORT-B: improving protein subcellular localization prediction for Gramnegative bacteria. Nucleic Acids Res 31, 3613-3617.

Glomski, I. J., Corre, J. P., Mock, M. \& Goossens, P. L. (2007). Cutting edge: IFN- $\gamma$-producing CD4 T lymphocytes mediate spore-induced immunity to capsulated Bacillus anthracis. J Immunol 178, 2646-2650.

Gominet, M., Slamti, L., Gilois, N., Rose, M. \& Lereclus, D. (2001). Oligopeptide permease is required for expression of the Bacillus thuringiensis plcR regulon and for virulence. Mol Microbiol 40, 963-975.

Goodin, J. L., Raab, R. W., McKown, R. L., Coffman, G. L., Powell, B. S., Enama, J. T., Ligon, J. A. \& Andrews, G. P. (2005). Yersinia pestis outer membrane type III secretion protein YscC: expression, purification, characterization, and induction of specific antiserum. Protein Expr Purif 40, 152-163.

Goossens, P. L., Sylvestre, P. \& Mock, M. (2007). Of spore opsonization and passive protection against anthrax - Microbiology Comment. Microbiology 153, 301-302.

Hahn, U. K., Boehm, R. \& Beyer, W. (2005). DNA vaccination against anthrax in mice - combination of anti-spore and anti-toxin components. Vaccine 24, 4569-4571.

Helmann, J. D. \& Moran, C. P., Jr (2002). RNA polymerase and sigma factors. In Bacillus subtilis and its Closest Relatives. From Genes to Cells, pp. 289-312. Edited by A. L. Sonenshein, J. A. Hoch \& R. Losick. Washington, DC: American Society for Microbiology.

Jackson, P. J., Walthers, E. A., Kalif, A. S., Richmond, K. L., Adair, D. M., Hill, K. K., Kuske, C. R., Andersen, G. L., Wilson, K. H. \& other authors (1997). Characterization of the variable-number tandem repeats in vrrA from different Bacillus anthracis isolates. Appl Environ Microbiol 63, 1400-1405.

Jedrzejas, M. J. (2002). The structure and function of novel proteins of Bacillus anthracis and other spore-forming bacteria: development of novel prophylactic and therapeutic agents. Crit Rev Biochem Mol Biol 37, 339-373.

Joellenbeck, L. M. \& Hernandez, L. M. (2002). The Institute of Medicine's independent scientific assessment of Gulf War health issues. Mil Med 167, 186-190. 
Johnson, Z. I. \& Chisholm, S. W. (2004). Properties of overlapping genes are conserved across microbial genomes. Genome Res 14, $2268-2272$.

Keim, P., Kalif, A., Schupp, J., Hill, K., Travis, S. E., Richmond, K., Adair, D. M., Hugh-Jones, M., Kuske, C. R. \& Jackson, P. (1997). Molecular evolution and diversity in Bacillus anthracis as detected by amplified fragment length polymorphism markers. J Bacteriol 179, 818-824.

Kim, H., Hahn, M., Grabowski, P., McPherson, D. C., Otte, M. M., Wang, R., Ferguson, C. C., Eichenberger, P. \& Driks, A. (2006). The Bacillus subtilis spore coat protein interaction network. Mol Microbiol 59, 487-502.

Krogh, A., Larsson, B., von Heijne, G. \& Sonnhammer, E. L. (2001). Predicting transmembrane protein topology with a hidden Markov model: application to complete genomes. J Mol Biol 305, 567-580.

Kudva, I. T., Griffin, R. W., Garren, J. M., Calderwood, S. B. \& John, M. (2005). Identification of a protein subset of the anthrax spore immunome in humans immunized with the anthrax vaccine adsorbed preparation. Infect Immun 73, 5685-5696.

Laflamme, C., Lavigne, S., Ho, J. \& Duchaine, C. (2004). Assessment of bacterial endospore viability with fluorescent dyes. J Appl Microbiol 96, 684-692.

Lemon, K. P. \& Grossman, A. D. (1998). Localization of bacterial DNA polymerase: evidence for a factory model of replication. Science 282, 1516-1519.

Leppla, S. H., Robbins, J. B., Schneerson, R. \& Shiloach, J. (2002). Development of an improved vaccine for anthrax. J Clin Invest 110, 141-144.

Little, S. \& Driks, A. (2001). Functional analysis of the Bacillus subtilis morphogenetic spore coat protein CotE. Mol Microbiol 42, 1107-1120.

Little, S. F. \& Knudson, G. B. (1986). Comparative efficacy of Bacillus anthracis live spore vaccine and protective antigen vaccine against anthrax in the guinea pig. Infect Immun 52, 509-512.

Little, S. F., Webster, W. M., Ivins, B. E., Fellows, P. F., Norris, S. L. \& Andrews, G. P. (2004). Development of an in vitro-based potency assay for anthrax vaccine. Vaccine 22, 2843-2852.

Mendelson, I., Tobery, S., Scorpio, A., Bozue, J., Shafferman, A. \& Friedlander, A. M. (2004). The NheA component of the non-hemolytic enterotoxin of Bacillus cereus is produced by Bacillus anthracis but is not required for virulence. Microb Pathog 37, 149-154.

Moir, A., Corfe, B. M. \& Behravan, J. (2002). Spore germination. Cell Mol Life Sci 59, 403-409.

Nicholson, W. L. \& Setlow, P. (1990). Sporulation, germination, and outgrowth. In Molecular Biological Methods for Bacillus, pp. 391-450. Edited by C. R. Harwood \& S. M. Cutting. New York: Wiley.

Pagni, M., loannidis, V., Cerutti, L., Zahn-Zabal, M., Jongeneel, C. V. \& Falquet, L. (2004). MyHits: a new interactive resource for protein annotation and domain identification. Nucleic Acids Res 32, W332-W335.

Paidhungat, M. \& Setlow, P. (1999). Isolation and characterization of mutations in Bacillus subtilis that allow spore germination in the novel germinant D-alanine. J Bacteriol 181, 3341-3350.

Pandey, N. K. \& Aronson, A. I. (1979). Properties of the Bacillus subtilis spore coat. J Bacteriol 137, 1208-1218.

Perez-Casal, J., Caparon, M. G. \& Scott, J. R. (1991). Mry, a transacting positive regulator of the $\mathrm{M}$ protein gene of Streptococcus pyogenes with similarity to the receptor proteins of two-component regulatory systems. J Bacteriol 173, 2617-2624.
Phillips, A. P. \& Ezzell, J. W. (1989). Identification of Bacillus anthracis by polyclonal antibodies against extracted vegetative cell antigens. J Appl Bacteriol 66, 419-432.

Pittman, P. R., Kim-Ahn, G., Pifat, D. Y., Coonan, K., Gibbs, P., Little, S., Pace-Templeton, J. G., Myers, R., Parker, G. W. \& Friedlander, A. M. (2002). Anthrax vaccine: immunogenicity and safety of a dosereduction, route-change comparison study in humans. Vaccine 20, 1412-1420.

Popov, S. G., Popova, T. G., Grene, E., Klotz, F., Cardwell, J., Bradburne, C., Jama, Y., Maland, M., Wells, J. \& other authors (2004). Systemic cytokine response in murine anthrax. Cell Microbiol 6, 225-233.

Rasko, D. A., Ravel, J., Okstad, O. A., Helgason, E., Cer, R. Z., Jiang, L., Shores, K. A., Fouts, D. A., Tourasse, N. J. \& other authors (2004). The genome of Bacillus cereus ATCC 10987 reveals metabolic adaptations and a large plasmid related to Bacillus anthracis $\mathrm{pXO1.} \mathrm{Nucleic} \mathrm{Acids} \mathrm{Res}$ 32, 977-988.

Read, T. D., Peterson, S. N., Tourasse, N., Baillie, L. W., Paulsen, I. T., Nelson, K. E., Tettelin, H., Fouts, D. E., Eisen, J. A. \& other authors (2003). The genome sequence of Bacillus anthracis Ames and comparison to closely related bacteria. Nature 423, 81-86.

Redmond, C., Baillie, L. W. J., Hibbs, S., Moir, A. J. G. \& Moir, A. (2004). Identification of proteins in the exosporium of Bacillus anthracis. Microbiology 150, 355-363.

Steichen, C., Chen, P., Kearney, J. F. \& Turnbough, C. L., Jr (2003). Identification of the immunodominant protein and other proteins of the Bacillus anthracis exosporium. J Bacteriol 185, 1903-1910.

Steichen, C. T., Kearney, J. F. \& Turnbough, C. L., Jr (2005). Characterization of the exosporium basal layer protein BxpB of Bacillus anthracis. J Bacteriol 187, 5868-5876.

Steinmetz, M. \& Richter, R. (1994). Easy cloning of mini-Tn10 insertions form the Bacillus subtilis chromosome. J Bacteriol 176, 1761-1763.

Sylvestre, P., Couture-Tosi, E. \& Mock, M. (2002). A collagen-like surface glycoprotein is a structural component of the Bacillus anthracis exosporium. Mol Microbiol 45, 169-178.

Sylvestre, P., Couture-Tosi, E. \& Mock, M. (2005). Contribution of ExsFA and ExsFB proteins to the localization of BclA on the spore surface and to the stability of the Bacillus anthracis exosporium. J Bacteriol 187, 5122-5128.

Vepachedu, V. R. \& Setlow, P. (2005). Localization of SpoVAD to the inner membrane of spores of Bacillus subtilis. J Bacteriol 187, $5677-5682$.

Welkos, S. L., Trotter, R. W., Becker, D. M. \& Nelson, G. O. (1989). Resistance to the Sterne strain of $B$. anthracis: phagocytic cell responses of resistant and susceptible mice. Microb Pathog 7, 15-35.

Welkos, S., Little, S., Friedlander, A., Fritz, D. \& Fellows, P. (2001). The role of antibodies to Bacillus anthracis and anthrax toxin components in inhibiting the early stages of infection by anthrax spores. Microbiology 147, 1677-1685.

Welkos, S., Friedlander, A., Weeks, S., Little, S. \& Mendelson, I. (2002). In-vitro characterisation of the phagocytosis and fate of anthrax spores in macrophages and the effects of anti-PA antibody. J Med Microbiol 51, 821-831.

Welkos, S. L., Cote, C. K., Rea, K. M. \& Gibbs, P. H. (2004). A microtiter fluorometric assay to detect the germination of Bacillus anthracis spores and the germination inhibitory effects of antibodies. J Microbiol Methods 56, 253-265.

Edited by: A. Fouet 